\title{
Discussion on the Teaching Reform of the Engineering Post-graduate Education
}

\author{
Zhou Danfeng*, Li Jie \\ College of Intelligence Science and Technology, National University of Defense Technology, Changsha, China
}

\section{Email address:}

zdfnudt@163.com (Zhou Danfeng),jieli@nudt.edu.cn (Li Jie)

${ }^{*}$ Corresponding author

\section{To cite this article:}

Zhou Danfeng, Li Jie. Discussion on the Teaching Reform of the Engineering Post-graduate Education. Science Innovation. Vol. 8, No. 3, 2020, pp. 60-64. doi: 10.11648/j.si.20200803.12

Received: April 18, 2020; Accepted: May 29, 2020; Published: June 8, 2020

\begin{abstract}
Post-graduate education is a major approach for the training of high-level personnel in China. However, compared with advanced foreign education systems, a disparity of the post-graduate student's training quality still exists. In this paper, based on the current post-graduate eduation status, the problems exist in the engineering post-graduate education are brought forward, from the aspects of the frontier knowledge, application ability, innovation ability, and academic communication ability. The reasons of the problems in the teaching process of the engineering post-graduate courses are mainly investigated, and the major aspects related to 'teaching' and 'learning' that influence the teaching effects are discussed. It is pointed out that the dismatch between the teaching, including contents and teaching method, and learning ability of the students is the main reason of these problems. To solve them, suggestions on the teaching reforms are proposed,including: selection of teaching contents, reform of teaching method, establishement of the feedback mechanism, change of learning method, and improvement of evaluation method, etc. A closed loop strcture of the entire post-graduate teaching approach is proposed as well. This work is benefit for improving the teaching effect of the engineering post-graduate courses, and it also provides a reference for the teaching reform of the engineering post-graduate education in the new engineering background.
\end{abstract}

Keywords: Engineering, Post-graduate, Teaching Reform

\section{工科研究生课程教学改革探讨}

周丹峰”, 李杰

国防科技大学智能科学学院, 长沙, 中国

邮箱

zdfnudt@163.com（周丹峰）, jieli@nudt.edu.cn（李杰）

摘要：研究生教育是中国培养高层次人才的主要途径。然而与国外先进水平相比, 国内的研究生培养质量尚存在较大 差距。本文针对我国当前研究生培养现状, 分别从前沿知识、应用能力、创新精神、学术交流能力方面指出当前工科 研究生教育存在的问题。针对这些问题的成因, 重点对工科研究生课程教学过程中的问题展开剖析, 分别从“教”和“学” 两方面分析影响教学效果的因素, 指出教学内容、教学方式与学生接受能力不匹配是产生问题的本质原因。为了解决 这些问题, 提出了对应的改革措施, 包括: 教学内容的取舍、教学手段的改革、构建反馈机制、改变学习方式、改革 考核方式等, 并提出了研究生课程教学全过程的闭环反馈结构。本文的研究有助于提高工科研究生课程教学效果, 为 新工科背景下研究生教学改革提供有益的参考。

关键词: 工科, 研究生, 教学改革 


\section{1. 引言}

教育部、国家发展改革委、财政部在《关于深化研究 生教育改革的意见》（教研[2013]1号）[1]中指出: “研究 生教育是培养高层次人才的主要途径, 是国家创新体系的 重要组成部分。”可见研究生教育在我国经济社会发展中 的地位之重。然而该《意见》同时也指出: “研究生教育 还不能完全适应经济社会发展的多样化需求, 培养质量与 国际先进水平相比还有较大差距”。从宏观上讲, 近十年 来, 我国在研究生的培养规模、培养层次上取得了可喜的 成果, 但从微观层面上看, 我国的研究生教育仍存在不少 值得改进的方面。具体到工科研究生培养层面, 与国际一 流大学相比, 国内的研究生培养在创新精神、实践能力、 把握学术前沿能力方面存在较大差距。本文针对工科研究 生教育过程中存在的问题, 尤其是研究生教学层面的问题 展开探讨, 指出产生问题的原因, 并提出针对性的改进建 议, 为工科研究生课程教学改革提供参考。

\section{2. 工科研究生教育教学中存在的问题}

目前, 我国的研究生教育已经成为培养高层次人才的 主要途径, 为各行各业的骨干力量生成提供了来源, 各大 高校均十分重视研究生教育和教师队伍的培养。如, 有些 高校要求硕士研究生能够掌握本专业或专业领域坚实的 基础理论和系统的专门知识, 具有从事科学研究或独立担 负专门技术工作的能力; 而对博士研究生则在硕士研究生 要求的基础上强调掌握本学科“坚实宽广”的理论基础和 “系统深入”的专门知识, 具备战略思维、国际视野和国际 竞争力。显然, 对研究生的培养要求不仅局限于对课本知 识的掌握, 还对研究生的知识深度、广度、应用能力和国 际视野均提出了很高的要求。

然而考察近年来的研究生综合能力发现, 虽然多数研 究生能够达到培养方案规定的学分要求, 但是在掌握“系 统深入的专门知识”以及“独立从事科学研究工作的能力” 方面存在明显不足。不少研究生 (包括博士研究生) 的国 际视野并不开阔, 缺乏国际竞争力。具体来说, 这些问题 体现在几个方面:

第一, 在实际工程中, 学生难以把研究生阶段的学习 内容应用到工程实际中。以控制科学与工程专业为例, 研 究生阶段开设的控制类课程通常可以涵盖本学科的热点 控制理论和方法, 开设的专业课程包括《非线性系统》、 《自适应控制》、《鲁棒控制》、《神经网络控制》、《随 机控制》、《最优控制》、《智能控制》等, 然而在课题 研究中, 很多研究生无法有效利用这些控制方法解决实际 控制问题。这主要归因于研究生阶段的知识掌握深度不足, 无法有效进行运用。

第二, 缺乏创新精神。对于面临的工程问题, 更倾向 于寻找书本或文献中已有的解决方法, 无法站在较高的高 度独立思考解决方法。
第三，无法把握本学科的前沿热点问题。很多研究生 没有养成阅读文献的习惯, 不了解相关学科的前沿热点问 题及研究方向。

第四, 学术交流能力欠缺。在大型学术交流交流会议 上, 很多研究生存在看不明、听不懂、说不清的问题。

虽然有些教育工作者认为研究生教育和本科教育存 在很大不同, 在课堂形式上也存在较大差异, 但课堂仍是 传授知识的最基本阵地。以上问题也说明当前的研究生教 育在课堂教学层面仍存在不足, 需要进行改革。

\section{3. 工科研究生教育教学问题的成因}

从参与教学过程的个体来说, 教师是“教”的主体, 学 生是“学”的主体, “教”和“学”密不可分, 两个方面均可能 导致研究生课程教学效果欠佳。

首先, 从“教”的角度来说, “教”是知识传授的主要途 径, 因此“教”的好坏直接决定着研究生课程教学的效果。 当前工科研究生教学过程存在的一个普遍问题是教学方 式过于单调、课堂氛围沉闷, 导致学生学习积极性差。工 科研究生课程通常更接近学科前沿, 具有一定的理论深度, 这就决定了学生在接受此类知识时存在一定的难度, 很容 易产生枯燥乏味的感觉。而传统的灌输式教学形式很容易 引发学生疲劳、走神的情况, 而这种情况又会进一步影响 对后续内容的接受, 导致课程学习出现“掉队”现象。例如, 在《自适应控制》课程教学中发现, 大部分学生一般在课 堂开始的前二十分钟能够较为专心地听讲, 随后便有越来 越多的学生出现分心走神的情况。从课后交流的反馈意见 来看, 有超过一半的学生认为该课程理论推导偏多、内容 复杂是引起课堂走神的重要原因。有超过 $1 / 3$ 的学生在反 馈意见中提议课程教学内容应多加入实例的讲解, 减少理 论推导的比重。因此, 如何有效地组织课堂教学内容、改 善课堂氛围、提高学生的学习积极性是研究生教学改革中 需要特别重视的问题。

其次, 从“学”的角度来说, 研究生课程的难度通常较 大, 对于理论性较强的课程, 无论是借助多媒体课件还是 采用常规板书的方法均无法保证学生在课堂有限的时间 内完全掌握抽象的理论知识。这就要求学生在学习此类课 程时, 不能仅依靠课堂讲授获得知识。实际上, 课堂上的 信息量往往会超过学生能够接受的信息容量, 从而导致信 息溢出。因此, 如何从“学”的角度改变现有的信息获取方 式是提高研究生教学效果的另一途径。

\section{4. 工科研究生课程教学改革方案探讨}

要提高工科研究生课程的教学效果, 必须在“教”和 “学”两个环节综合进行改革, 并适当改进研究生课程的考 核方式。下面针对这些方面分别开展探讨。

\section{1. 教学内容的取舍}

有的高校研究生培养方案在课程设置上讲究“充分反 映学科内涵、学科基础和学科前沿”, 力求提高课程的“含 
金量”。因此, 研究生课程在讲解内容上应遵循少讲精讲、 粗细结合的原则。研究生课程不同于本科课程, 不要求面 面俱到。对于学生而言, 经过本科阶段的学习和训练, 研 究生在学习能力、知识理解能力上均有很大提高, 在有限 的课堂时间上更应注重对于核心、难点知识的剖析, 而对 于一些理解难度不大的知识可以留给学生自己学习, 避免 低水平和咒余性内容的讲授。然而, 工科研究生课程内容 中常存在一些非常复杂的推导和证明, 这些内容即使在课 堂上花费很多时间进行讲述也不一定能够取得很好的效 果, 这类内容宜作为扩展内容由学生在课下自学。在文献 [2]中, 针对《自动控制原理》课程出现的学生学习难度大、 兴趣低的问题, 石建平等主张更新课程理念、大力简化教 学内容。这一做法在研究生课程教学中同样值得借鉴。

此外, 对教师自身而言, 研究生课程需要教师在知识 的深度和广度上要有足够的储备。研究生课程不仅仅是教 授课本上的知识, 更重要的是让学生了解本专业当前的研 究现状、应用现状、前沿热点问题等。对于应用性较强的 课程, 要求教师自身有足够丰富的工程应用经验。这些课 本外的知识往往更能调动学生的学习积极性, 也是改善课 堂气氛的重要手段。为了开拓学生的知识面, 可以在授课 内容中加入相关的学科前沿知识和交叉学科知识, 在条件 具备的情况下可以借助科研创新平台、学科交叉平台等扩 展学生的知识面。文献[3]对学科交叉平台、科技创新平台 和科技竞赛平台的作用展开论述, 指出它们在培养研究生 的科研和创新能力方面的作用。

\section{2. 改革教学手段}

课堂氛围沉闷是影响教学效果的重要问题。因此在教 学手段上, 要体现多样性、趣味性、交互性。首先, 良好 的课堂氛围需要课堂的主体 (即教师和学生) 共同创造。 对于教师而言, 要做好课堂设计, 在课堂上营造良好的互 动氛围、引导学生主动思考。其次, 在授课方式上, 要改 变单纯以知识灌输为主的教学形式。近年来, 很多教育工 作者对于教学手段提出了很多改革措施, 如启发式教学[4]、 案例教学[5-7]、研讨式教学 [8,9]、实践教学模式[10]等。 这些方法都可以作为研究生课程教学中改善教学效果的 手段。对于工科研究生课程来说, 创新能力和实践能力是 培养的重要目标, 因此在教学方式上更应注重将工程案例 引入课堂, 体现教学内容的实用性, 提升学生学习的兴趣。

再如, 互联网技术的发展催生了类似“雨课堂”、网络 会议平台这样的网络化互动教学手段, 丰富了课堂上“教”、 “学”互动手段, 是一种值得肯定的创新模式。2020年初的 新冠病毒疫情影响促使线上教学成为教师授课的一种新 模式, 其交互性、实时性都为课堂教学带来了新的体验。 可以预见, 随着互联网、人工智能时代的来临, 网络化、 线上线下、课上课下交互式教学的手段将会越来越成熟, 必将使传统课堂的界限模糊化, 这就要求教师在掌握信息 化教学手段和课程设计上与时俱进, 跟上时代潮流。

笔者根据多年的研究生教学经验发现, 图文并茂、生 动活泼的课件、清晰明了的推到过程、直观形象的案例、 简洁形象的表述仍是增加学生学习兴趣、有效提升知识传 输“带宽”的根本途径。回归课堂、回归讲授是研究生教学
需要重视的方面。文献[11]对《自适应控制》研究生课程 的教学问题进行了剖析, 进而对研究生课堂教学手段提出 了改进意见, 包括多媒体教学形式在复杂工科课程中的应 用建议、案例教学和启发式教学在公式繁多的研究生课程 中的应用等。但该文献对研讨型教学形式在理论性较强的 研究生课程中的应用效果持保留态度, 认为这种教学方式 利弊参半。

此外, 课堂节奏的把握对于学生的知识接受能力也有 很大影响。有些教育学者根据长期的教学实践总结发现, 对于理论性较强的课程, 学生能够集中精力地连续听讲的 时间通常不超过 15 分钟。这要求教师在课堂上连续讲授知 识的时间最好不要超过 15 分钟, 中间应当贯穿一些讨论、 交互、自学等环节。

\section{3. 构建反馈渠道}

在控制理论中, 反馈是非常重要的概念, 它可以消除 误差, 使系统的输出跟踪期望的输入。反馈的作用对于教 学过程也是如此。构建学生学习状况的反馈渠道可以实时 掌握学生的学习状况、发现教学过程的不足, 并有的放矢 进行教学调整。这些反馈渠道包括: 课堂上的问卷和测试 卡片、每次课后的交流和答疑环节、以及课程结束时的书 面的反馈意见等。从实践效果来看, 课程结束后的反馈意 见往往能够真实反映学生在学习本门课程时遇到的困难、 产生的原因等问题, 不少学生还会提出相关建议, 这些反 馈信息对于提高课程的教学效果具有十分重要的意义。

随着微信、雨课堂等信息化传递手段的日益普及，学 生和教师之间的反馈渠道越发多元化和普遍化, 这种多元 反馈渠道可以贯穿课程的预习、讲授、复习答疑、考核全 流程, 对于教师的专业素质提出了新的要求。

\section{4. 改变学习方式}

单纯的“教”并不能达到效果最大化, “教”“学”相长才 能有效提高学生的学习效率。“灌输式”教学往往会使学 生出现知识接受能力“饱和”的现象, 随着课堂的推进, 学 生的信息接受能力逐渐下降。适当的自学可以使学生在课 堂上带着问题寻找答案, 其效果也会更好。最近很多教育 学者提出“翻转课堂”的概念, 在教学方法上以学生课前自 学为主, 课堂答疑为辅。它要求学生在课下花费大量的时 间进行自学, 归纳学习过程中遇到的问题。这种方法对于 有些课程可以收到很好的效果。例如, 陶洪峰[12]提出在 《自动控制原理》课程中开展翻转课堂与引导式教学相结 合的教学方法, 改变单纯由老师授课、学生听讲的传统课 堂形式, 可以增加学生的学习自由度。文献[13]对翻转课 堂应用于数学专业硕士研究生的教学改革中进行了探讨 和尝试, 从内容的选取、课堂的组织、课下网络工具的应 用等方面进行了探讨, 认为这种教学模式是未来研究生教 学改革的一个推广方向。然而这一教学方式要充分考虑学 生的课业负担、课外能支配的学习时间、学生的自律性等 因素, 在学生自学的内容、比例方面需要仔细勘酌。在新 型传感器原理及应用研究生课程教学改革探索中, 刘春阳 等人 [14]在每次课前会安排10分钟时间让学生对调研的内 容进行讲解, 实现课堂的部分翻转。这种方法是值得借鉴 
的, 但是在多大程度上进行翻转则需要根据课程的特点、 尤其是学生的课业承担能力灵活安排。

综合上述教学改革措施, 结合部分翻转课堂的理念, 工科研究生教学过程应当形成“课前一一课中一一课后” 闭环结构, 如图1所示。图中方框中的所有环节构成课堂 教学环节, 椭圆表示的环节则为课下环节, 虚线表示在不 同的教学环节中参与主体 (包括教师和学生两部分) 对应 的归属关系。显然, 对于有共同交点的教学环节, 是属于 师生共同参与完成的环节。值得说明的是, 根据课程教学 内容的不同, 方框中的课堂教学环节具体内容也应按照实 际情况灵活安排。

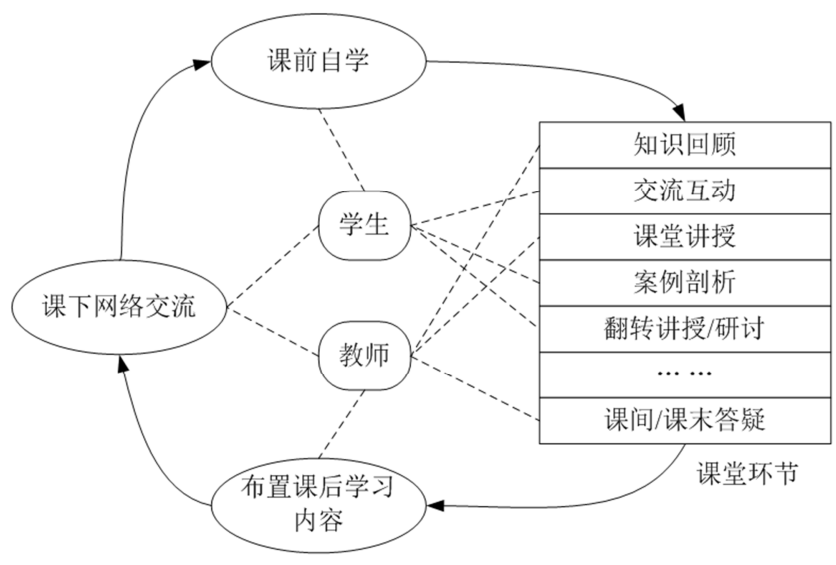

图1 研究生教学过程的闭环结构。

\section{5. 改革考核评价方式}

对于教学过程来说, 考核是学生学习的指挥棒。鉴于 研究生培养的目标是重点培养学生的创造能力和实践能 力, 因此在考核方面不能仅仅考察学生对理论知识的掌握 程度。研究生课程的考评不能仅仅把笔试的闭卷考试作为 衡量学生学习好坏的唯一标准, 还应综合考察学生的课堂 表现、汇报展示、大作业、论文等表现, 并以加权的形式 综合评判学生的最终成绩[3]。这种方法可以避免单项评估 产生的误差。然而, 在实践中发现, 对于大作业或课程设 计类的题目, 有时很难区分不同学生对于相同问题的理解 程度, 这类题目的解答和判读往往具有较大的主管性, 存 在一定的弊端。因此, 在题目的设计上, 既不能脱离对课 程基本知识的考察, 又必须具有一定的扩展性和新颖性。

此外, 由于把握学术前沿是对研究生培养的重要要求 之一, 因此, 在考核层面可以适当加强对学生文献阅读数 量和质量方面的考察。在培养管理层面, 则应当以制度性 文件的形式对研究生参加学术交流活动的等级和次数进 行明确。如文献[15]从制度层面对学科交叉力度和课外学 分的考核和认定进行了研究, 这种方式有利于督促学生开 拓视野和扩展知识面, 构建完备的知识体系。再如, 我校 的培养方案明确要求“博士生至少应参加一次国际学术会 议或国内高水平学术会议并发表论文”。这是对研究生参 加学术交流的最低要求。实际上, 国内外和专业相关的学 术会议, 在条件允许的情况下应鼓励研究生出国参加高级 别的学术会议并进行交流, 这不仅可以提高研究生的论文 写作能力、知识应用能力, 更重要的是可以了解国际上对
相关专业的研究现状, 查找自身的不足和差距, 增强学习 的主动性和针对性。

\section{5. 结论}

研究生教育对于我国的高层次人才队伍建设具有 决定性作用。随着社会的发展, 我国社会对研究生人才 的素质需求提升到了新的高度。然而, 我国的研究生教 育水平与国外先进国家相比还有较大差距, 很多高校过 分注重本科教育质量而忽视了研究生教学质量, 在这个 背景下如何提高研究生培养的效果是摆在高校面前的 现实问题。本文主要针对工科研究生的教学问题开展探 讨, 从教学内容的取舍、教学手段的改革、构建反馈机 制、改变学习方式、改革考核方式等方面提出教学改革 建议, 并提出了研究生课程教学全过程的闭环反馈结构, 目的在于改变现有工科研究生的培养现状, 提升工科研 究生的专业素质, 为培养适合社会发展的新型高层次科 技人才提供参考。

实际上, 影响研究生课程教学效果的因素往往不是单 一的, 教、学、管每个环节的设定均会对最终效果产生影 响。要真正大幅提高工科研究生的培养质量, 不仅要在课 堂教学方面进行改革, 更要在学科规划、学生管理、法规 制定以及配套的条件保障等层面予以配合。

\section{致谢}

本文为国家十三五重点研发计划子任务 (2016YFB1200601-B12) 的成果之一。

\section{参考文献}

[1] 教育部, 国家发展改革委,财政部、《关于深化研究生教育改 革 的 意见》(教 研〔2013) 1 号）.http://old.moe.gov.cn/publicfiles/business/htmlfiles/moe/ A22_zcwj/201307/154118.html。

[2] 石建平, 刘鹏.新工科背景下自动控制原理课程教学改革[J]. 教育教学论坛, 2019, 8:138-139。

[3] 王秀芳, 高丙坤, 姜春雷, 陈朋, 江洪波.新工科背景下提 高研究生创新能力的培养模式研究 [J]. 中国现代教育装备, 2020, 331: 38-42。

[4] 陈善勇,戴一帆,彭小强,解旭辉. “回归工程”背景下的《数字 化制造技术》研究生课程改革探索[J]. 高等教育研究学报, 2009 , 第32卷增刊: $37-39,45$ 。

[5] 孔庆军. 基于激发研究生的学习动力与兴趣的课程改革研 究[J].教育教学论坛, 2018, 43: 130-131。

[6] 刘志刚,赵舵. 研究生信号处理课程改革研究 [J]. 电气电子教 学学报,2011,33(2):32-33。 
[7] 党薇, 李宏林, 董贵荣.案例教学在《理论力学》中的应用 探索 [J].创新教育研究, 2019, 7(4): 487-490。

[8] 卢瑾. 国外高校研讨课程对我国高校教学改革的启示 [J]. 新课程研究, 2018(9): 9-11,33。

[9] 秦川, 杜静雅.工程硕士专业学位研究生科技翻译课程教学 改革[J].中国治金教育，2019(3)：16-18。

[10] 吴鹏,徐乐中,沈耀良.专业学位研究生实践教学模式改革研 究[J].黑龙江教育, 2019，1275(3)：86-88。

[11] 周丹峰, 李杰. 研究生课程《自适应控制》教学改革探讨 [J].Science Innovation，2019，7(2): 59-63。
[12] 陶洪峰.自动控制原理课程的混合式教学模式探索 [J].大学 教育, 2019, 3:62-64。

[13] 赵侯宇. 数学专业硕士研究生教学改革初探 [J]. 科技 风,2019,2019(1): 19,25。

[14] 刘春阳,黄艳,蔡海潮,尚振东,徐巧玉,徐彦伟,徐恺.新型传感 器原理及应用研究生课程教学改革与探索 [J].中国现代教 育装备，2019，311：39-41。

[15] 李翠敏, 王晓春. 新工科背景下地方高校人才培养新模式 探索 $[\mathrm{J}]$.大学教育, 2020, 4: 154-156。 